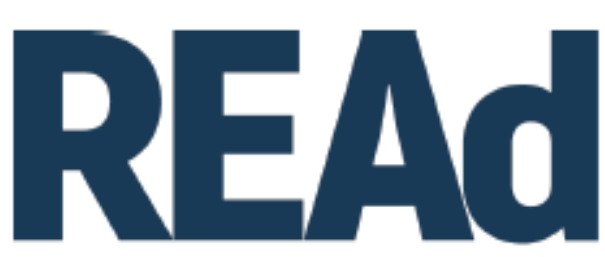

Revista Eletrônica de Administração

\title{
O EFEITO DA INCERTEZA POLÍTICA NO DESEMPENHO E VALORAÇÃO DAS COMPANHIAS ABERTAS BRASILEIRAS ${ }^{1}$
}

\author{
Márcia Formiga ${ }^{2}$ \\ Claudio Marcelo Edwards Barros ${ }^{3}$ \\ Nathiele de Jesus Cezário ${ }^{4}$ \\ Luciano Marcio Scherer 5
}

http://dx.doi.org/10.1590/1413-2311.270.96608

\section{RESUMO}

O objetivo deste trabalho consistiu em examinar o efeito da incerteza política observado no Brasil nos anos de 2014 a 2016 sobre o desempenho econômico e valoração das companhias abertas. Esta pesquisa contribui para a evolução do conhecimento sobre a temática incerteza política, bem como para aprofundar a análise dos resultados apresentados por estudos que buscaram mensurar e demonstrar os efeitos produzidos por um ambiente de elevada incerteza política e como isso é capaz de afetar tanto a economia como as finanças corporativas. Para indicar o período de incerteza política, a pesquisa utilizou os relatórios Global Ratings para América Latina da Standard and Poors emitidos entre 03/2014 e 02/2016. Para determinação do desempenho econômico, as variáveis dependentes do estudo foram ROE, ROA, ROI, EVA e Ebitda. Para valoração, utilizou-se o Q de Tobin, MVA e Price to Book. A amostra foi composta por 4.658 observações de companhias abertas brasileiras para o período entre 2011

\footnotetext{
${ }^{1}$ Recebido em 20/9/2019, aceito em 21/10/2019.

2 Universidade Federal do Paraná (UFPR) - Programa de Pós Graduação em Contabilidade - Curitiba - PR (Brasil); http://orcid.org/0000-0002-6207-0675; marcia-formiga@ hotmail.com

${ }^{3}$ Universidade Federal do Paraná (UFPR) - Programa de Pós Graduação em Contabilidade - Curitiba - PR (Brasil); http://orcid.org/0000-0001-7431-1627; claudiomedwards@ hotmail.com

${ }^{4}$ Universidade Federal do Paraná (UFPR) - Programa de Pós Graduação em Contabilidade - Curitiba - PR (Brasil); http://orcid.org/0000-0002-3913-7552; nathicezario@gmail.com

${ }^{5}$ Universidade Federal do Paraná (UFPR) - Programa de Pós Graduação em Contabilidade - Curitiba - PR (Brasil);http://orcid.org/0000-0002-6104-7860; 1mscherer.ufpr@gmail.com
} 
a 2016. Utilizou-se estatística descritiva, testes não paramétricos, análise fatorial e regressão múltipla com dados em painel. Alinhado aos estudos prévios e de acordo com o esperado, observaram-se evidências de que o nível elevado de incerteza política alcançou a atividade econômica na forma de queda de desempenho e destruição do valor de mercado de empresas brasileiras. Estes resultados se mostraram robustos à utilização do índice EPU (Economic Policy Uncertainty) proposto por Baker, Bloom e Davidson (2013).

Palavras-chave: Desempenho econômico. Incerteza política. Valoração.

\title{
THE EFFECT OF POLITICAL UNCERTAINTY ON THE PERFORMANCE AND VALUATION OF BRAZILIAN COMPANIES
}

\begin{abstract}
The objective of this study was to examine the effect of political uncertainty observed in Brazil from 2014 to 2016 on the economic performance and valuation of Brazilian companies. This research contribute to the evolution of knowledge on political uncertainty, as well as to deepen the analysis of the results presented by studies that sought to measure and demonstrate the effects produced by an environment of high political uncertainty and how this is capable of affect both the economy and corporate finance. To indicate the period of political uncertainty, the survey used the Standard and Poors' Global Ratings for Latin America reports between 03/2014 and 02/2016. To determine the economic performance, the variables dependent on the study are ROE, ROA, ROI, EVA and Ebitda. For valuation, we used Tobin's Q, MVA and Price to Book Ratio. The sample consisted of 4,658 observations of Brazilian public companies for the period between 2011 and 2016. Descriptive statistics, nonparametric tests, factorial analysis and multiple regression with panel data were used. Aligned with the previous studies and in line with what was expected, there was evidence that the high level of political uncertainty reached the economic activity in the form of a drop in performance and destruction of the market value of Brazilian companies. These findings are robust to the application of EPU (Economic Policy Uncertainty) index proposed by Baker, Bloom and Davidson (2013).
\end{abstract}

Keywords: Economic performance. Political uncertainty. Valuation. 


\title{
EL EFECTO DE LA INCERTIDUMBRE POLÍTICA SOBRE EL DESEMPEÑO Y LA VALORACIÓN DE LAS COMPAÑÍAS ABIERTAS BRASILEÑAS
}

\author{
RESUMEN
}

El objetivo de este estudio fue examinar el efecto de la incertidumbre política observada en Brasil entre 2014 y 2016 sobre el desempeño económico y la valoración de las empresas brasileñas. Esta investigación contribuye a la evolución del conocimiento sobre la incertidumbre política, así como a profundizar el análisis de los resultados presentados por estudios que buscaron medir y demostrar los efectos producidos por un entorno de alta incertidumbre política y cómo esto puede afectar tanto a los economía y finanzas corporativas. Para indicar el período de incertidumbre política, la encuesta utilizó los informes de calificaciones globales de Standard and Poors para América Latina entre el 20/03/2014 y el 02/2016. Para determinar el desempeño económico, las variables que dependen del estudio son ROE, ROA, ROI, EVA y Ebitda. Para la valoración, utilizamos Q, MVA y relación precio / libro de Tobin. La muestra consistió en 4,658 observaciones de empresas públicas brasileñas para el período comprendido entre 2011 y 2016. Se utilizaron estadísticas descriptivas, pruebas no paramétricas, análisis factorial y regresión múltiple con datos de panel. En línea con los estudios previos y en línea con lo que se esperaba, había evidencia de que el alto nivel de incertidumbre política alcanzó la actividad económica en forma de una caída en el rendimiento y la destrucción del valor de mercado de las empresas brasileñas. Estos hallazgos son sólidos para la aplicación del índice EPU (incertidumbre de política económica) propuesto por Baker, Bloom y Davidson (2013).

Palabras clave: Desempeño económico. Incertidumbre política. Valuación.

\section{INTRODUCAO}

O objetivo desta pesquisa foi examinar os efeitos do período de incerteza política observado no Brasil nos anos de 2014 a 2016 sobre o desempenho econômico e a valoração das companhias brasileiras.

Embora em 2008 o mundo tenha observado o desencadeamento da crise do subprime, 
considerada a maior crise econômica da história recente, no início daquele ano a crença sobre a propagação de um ciclo virtuoso de crescimento da economia brasileira se mostrava forte. Tal otimismo se sustentava em fatos concretos: Em abril de 2008, pela primeira vez, o Brasil tinha o rating de crédito soberano de sua dívida elevado a grau de investimento pela agência de classificação de risco Standard and Poors $(S \& P)$. A 14 edição da revista inglesa "The Economist", de novembro de 2009, estampou a estátua do Cristo Redentor, análoga à decolagem de um foguete em reportagem intitulada "Brasil decola", em que se realçava a estabilidade política e social do país.

No entanto, o Produto Interno Bruto (PIB) no último trimestre de 2008 e primeiro de 2009 apresentou queda de 4,09\% e 1,80\%, respectivamente, o que tecnicamente sugere um cenário de recessão, com o ano de 2009 fechando em retração de $0,2 \%$.

Diversas medidas de política fiscal intermediadas por bancos públicos e direcionadas à expansão de gastos do governo e incentivos ao consumo, além de redução de tributos, foram tomadas a partir de 2009, e em teoria, contribuíram para a expansão superior a $7 \%$ do PIB em 2010, 4\% em 2011 e 1,92\% em 2012.

Em 2013 o ritmo do crescimento econômico do Brasil começou a ser questionado, principalmente em função do viés expansionista da política fiscal. Em junho daquele ano a $S \& P$, por meio do relatório Global Ratings, destinado a fundamentar opiniões sobre o rating soberano da dívida brasileira, pela primeira vez desde a sua elevação para grau de investimento e antes de outras agências mundiais de classificação de risco, alterou para negativa a perspectiva do rating soberano. As razões para essa mudança de perspectiva foram o fraco desempenho da economia, aliado à trajetória de aumento da taxa básica de juros (Selic), dados os sinais de aumento da inflação.

O ano de 2014 foi desfavorável. Como mostrou a edição do Global Ratings de março daquele ano, a $S \& P$ rebaixou a nota do rating soberano para o nível mais baixo dentre as notas de graduações de grau de investimento e manteve perspectiva negativa. Sem qualquer relação com o conteúdo das opiniões da $S \& P$, foi iniciada a Operação Lava Jato, que apurou desvios de recursos da companhia estatal Petrobrás por meio de contratos fraudulentos e licitações arranjadas envolvendo agentes públicos, executivos do setor público e do setor privado.

Durante os anos de 2014 e 2015 ocorreram várias delações premiadas no campo da Operação Lava Jato, com revelações desestabilizadoras a políticos de vários partidos. No ano de 2015 a tendência de ascensão da inflação e taxa de juros se manteve e passou a compor um 
cenário de trimestres seguidos de queda do PIB e atípica volatilidade cambial, além da deterioração fiscal que se tornou ainda mais profunda. $O$ governo viu-se em dificuldades para se manter apartado de um volume crescente de políticos da cúpula dos partidos da base aliada envolvidos nas investigações em andamento. No segundo trimestre de 2015 o Brasil novamente entrou em recessão técnica e na edição de julho do Global Ratings, a $S \& P$ alterou para negativa a perspectiva do rating de crédito soberano.

Na edição de setembro de 2015 do relatório Global Ratings, a $S \& P$ anunciou a perda do grau de investimento do rating de crédito soberano da dívida brasileira. Como é possível observar no conteúdo do relatório, a $S \& P$ fez constar como fundamentação para redução a grau especulativo, o posicionamento da agência sobre as instituições políticas do Brasil em dois aspectos. Em primeiro, a incerteza política, por conta de investigações das alegações de corrupção contra indivíduos e empresas do setor público e privado de grande aproximação com o governo, além da provável homologação do pedido de impeachment da presidente; e em segundo, o fraco desempenho econômico, tendo em vista a retração do PIB de 3,5\% em 2015 e a perspectiva de queda também para 2016, associado à evolução de um quadro de expansão da inflação acima das metas estabelecidas pelo governo.

Diante da descrição deste contexto é possível notar nos relatórios Global Ratings da $S \& P$ divulgados entre 2014 e 2016 o fortalecimento de conteúdos que ligaram a deterioração da economia à evolução do quadro de incerteza política no Brasil. Ainda que as opiniões reveladas pela Agência não fossem específicas sobre reflexos no nível das empresas, o domínio expressivo da incerteza mostrada pelos posicionamentos da agência apontava para o agravamento de um quadro não somente restrito à administração pública federal, mas potencialmente capaz de atravessar as corporações.

O debate sobre a associação entre política e desempenho econômico não é recente no ambiente da pesquisa em finanças (BIALKOWSKI; GOTTSCHALK; WISNIEWSKI, 2008; JULIO; YOOK, 2012; PÁSTOR; VERONESI, 2012). Julio e Yook (2012) argumentaram que os incentivos e as incertezas circunscritas às possíveis mudanças na política econômica e na própria liderança nacional têm implicações sobre o comportamento de agentes políticos e empresas. Os autores consideraram que a essência da incerteza política está em como os governantes irão modelar políticas para estimular o nível de investimento privado no curto prazo e em como irão formular políticas regulatórias no longo prazo.

No caso do Brasil, nos anos de 2014, 2015 e 2016, percebeu-se um cenário em que a instabilidade política alcançou proporções extremas diante de persistentes indícios de 
corrupção envolvendo agentes políticos e empresas públicas e privadas. Este cenário combinou-se à deterioração de indicadores fundamentais da economia, sugerindo que a incerteza pode ter alcançado a estabilidade macroeconômica, o que também apresenta elevado potencial para alcançar o ambiente microeconômico, notadamente o desempenho das empresas brasileiras. Nesta direção, a questão de pesquisa que norteia este estudo é: Quais efeitos são observados sobre o desempenho econômico e a valoração das empresas brasileiras diante do cenário de incerteza política observado nos últimos anos no Brasil?

Esta pesquisa apresentou indícios de que o desempenho e a valoração das empresas abertas brasileiras foram influenciados pela incerteza política presente no contexto nacional a partir de 2014. Isto foi apontado pela relação negativa e estatisticamente significativa a $1 \%$ da variável dummy $\mathrm{DIP}_{\mathrm{t}}$, representativa dos períodos de incerteza política, conforme estabelecidos a partir da análise dos relatórios da $S \& P$, com o desempenho e a valoração das empresas analisadas neste estudo. Cabe observar que esses achados são confirmados em testes de robustez, quando, alternativamente se considerou a variável EPU Index como proxy para a incerteza política.

Portanto, este estudo apresenta pelo menos duas contribuições. A primeira está em apresentar indícios sobre como as empresas podem ser atingidas quando lideranças políticas perdem a capacidade de dar respostas que mostrem ao investidor a direção dos rumos da economia do país. A segunda está em contribuir para literatura no campo do ambiente econômico da contabilidade por meio da observação empírica de padrões de relacionamento entre variáveis contábeis e financeiras no nível da firma e proxies de incerteza política.

\section{REFERENCIAL TEÓRICO}

\subsection{INCERTEZA POLÍTICA}

A incerteza decorre de fatos que estão além da racionalidade humana, quando não há informações sobre as perspectivas futuras, não sendo capaz de prever e calcular a probabilidade de sua ocorrência, como obsolescência ou inovação tecnológica, lucros extraordinários, depressão, recessão, crises e guerras (KEYNES, 1937; DAVIDSON, 1991; SCHUMPETER, 1997).

Para alguns autores, incerteza e risco estão relacionados, embora produzam efeitos distintos na economia. $\mathrm{Na}$ literatura, estabelece-se que o risco está associado à probabilidade 
de o evento acontecer, podendo ser medido ou quantificado, embora seus resultados sejam desconhecidos. Já a incerteza apresenta eventos que não se sabe como e nem quando irão ocorrer, não sendo possível descrevê-la estatisticamente (COSTA FILHO, 2014).

A Teoria da Nova Economia Institucional (NEI) destaca a existência de incertezas no ambiente econômico devido à presença de assimetrias informacionais por parte dos agentes envolvidos, e esta assimetria é considerada como um dos elementos que contribui para o nível de incerteza, além da complexidade dos ambientes e da própria racionalidade limitada. Para Williamson (1985) estas incertezas significam os custos de funcionamento do sistema econômico e para North (1992) são as causas dos custos de transação. Ou seja, trata-se de conceito similar à teoria da agência, que relaciona além dos custos de transação, o autointeresse e a própria assimetria, que pode ser reduzida com o apoio dos agentes intermediários, por meio de projeções, descrição de fatores de risco, e cobertura de analistas de rating de crédito (RODRIGUES; GALDI, 2017).

Diante de incertezas, os investidores preferem adotar uma estratégia racional e agir por mimetismo, adequando seus comportamentos de acordo com os padrões estabelecidos pela maioria. Esse comportamento foi analisado por Keynes (1996) ao concluir que na presença de incerteza, desde que os mercados sejam organizados e confiáveis, os investimentos estarão mais seguros e os investidores tomarem decisões com base nas convenções definidas de acordo com o senso comum.

Quando a incerteza está relacionada à política, ou seja, em como o governo irá moldar as políticas públicas para estimular o investimento no curto prazo e como irá formular a política regulatória e econômica no longo prazo, as empresas podem adotar uma posição de espera, reduzindo os níveis de investimento e contratação de mão de obra até que a incerteza seja dissipada ou reduzida (JULIO; YOOK, 2012). Da mesma forma, em um ambiente de incerteza as empresas devem adiar suas decisões de investimentos em benefício de maiores retornos obtidos pela espera de mais informações (BERNANKE, 1983). Como a decisão dos investidores acaba refletindo no mercado financeiro, o Estado acaba intervindo para manter o funcionamento do sistema econômico, como meio de equilibro visando manter os níveis de produto, renda e emprego, socializando os riscos de incertezas (KEYNES, 1996).

Pástor e Veronesi (2012) destacam que a incerteza política está relacionada aos custos políticos, ou custos associados às novas políticas, que por serem difíceis de mensurar geram incerteza quanto às políticas que efetivamente devem ser adotadas. O governo procura analisar os custos para maximizar o bem-estar dos investidores, mas deve optar pela melhor 
escolha da política governamental que seria a adoção da política de menor custo.

\subsection{INCERTEZA NO AMBIENTE ECONÔMICO BRASILEIRO}

Os efeitos das incertezas no cenário brasileiro à luz da Teoria do Desenvolvimento Econômico de Schumpeter (1997) se comportaram de forma semelhante ao ciclo econômico analisado pelo autor. Para ele, todo boom é seguido por uma depressão e vice-versa, mas neste último o cenário de incerteza permanece enquanto a economia se prepara para um novo ciclo de equilíbrio. $\mathrm{O}$ ciclo econômico demonstra que os booms econômicos levam às crises que, por sua vez, podem conduzir a uma depressão.

Os ciclos econômicos decorrem da instabilidade no mercado financeiro. O boom surge quando as instituições financeiras impulsionam a economia reduzindo as taxas de juros e incentivando os empréstimos, produzindo um aumento no consumo e nas vendas realizadas pelo comércio e indústria. Este ciclo dá lugar à crise quando a liberação do crédito é reduzida e as taxas de juros elevadas, causando endividamento, além da redução dos lucros, prejuízos e falências em todos os setores envolvidos. Neste momento, os preços tendem a cair e as relações de mercado a se ajustar até encontrar o equilíbrio, eliminando os excessos causados pelo boom e adequando as distorções e erros gerados em decorrência dos preços elevados (ROTHBARD, 2009). Gulati, Nohria e Wohlgezogen (2010) estudaram 4.700 empresas e observaram que durante a crise $17 \%$ não resistem, $80 \%$ das que sobrevivem, não conseguem se recuperar antes de 3 anos, e $40 \%$ delas não consegue obter o mesmo nível de vendas e lucros, e somente $9 \%$ delas conseguem se recuperar.

Redesenhando a teoria de Schumpeter (1997) para o cenário brasileiro, é perceptível que as políticas de incentivo ao crédito financeiro e ao consumo produziram um boom econômico que estimulou uma crise, afetando a queda dos indicadores econômicos e financeiros. O período de boom brasileiro ocorreu enquanto o mundo estava atento e preocupado com a crise financeira mundial, em 2008. Neste período o Brasil apresentou um crescimento acima da média, com receitas inesperadas do boom das commodities, ostentando o melhor desempenho em décadas, reforçando suas relações e tendo maior relevância no cenário internacional. Com isso, o modelo econômico proporcionou a distribuição de renda, a expansão do crédito e do consumo (DE PAULA, 2011; LEAHY, 2011).

Mesmo num ambiente de prosperidade, não seria insensato considerar que em algum momento o Brasil poderia ser afetado pela crise mundial. Sendo assim, foi um dos últimos 
países a sentir os efeitos da crise, o que foi suficiente para contribuir com a desaceleração do crescimento brasileiro. A revista "The Economist" publicou em outubro de 2015 que as causas imediatas da crise brasileira foram externas, principalmente pelo fraco desempenho da China e pela queda no preço das commodities, embora fatores internos tenham contribuído para o desequilíbrio das contas públicas.

As análises de Schumpeter (1997) demonstraram que após um aumento considerável no nível de investimento seguido de prosperidade econômica haveria uma redução do nível de emprego, produção e investimento, o que de fato ocorreu no cenário brasileiro. E embora as crises estabelecidas nos demais países tenham as suas características distintas da que atingiu o Brasil, elas são um mesmo e único fenômeno e causa de desequilibro do desenvolvimento econômico. O que a teoria não justificou e, talvez nenhuma teoria possa explicar estatisticamente, a regularidade com que as crises ocorrem, mesmo porque cada economia tem um período do ciclo econômico. Apesar disso, ainda que não seja possível afirmar precisamente o momento em que as crises aparecem, os seus efeitos na economia podem ser investigados, os ciclos que as antecedem podem ser analisados e medidas preventivas podem ser adotadas antes do seu surgimento.

\subsection{INCERTEZA POLÍTICA E O MERCADO DE CAPITAIS}

A incerteza tem provocado efeitos negativos no desempenho da economia e das empresas, tendo sido objeto de estudo de pesquisadores e demais interessados na busca de um maior conhecimento sobre o que é e como pode ser utilizada na criação de políticas. A própria definição de incerteza na economia ainda causa confusão, e o seu conceito relacionado ao governo é considerado recente, sabe-se somente que o governo é uma fonte de incerteza. Estudos relataram que as incertezas relacionadas ao governo deixam os investidores indecisos, afetando o mercado financeiro e a economia (MORDFIN, 2014).

A elevada incerteza política nos Estados Unidos e na Europa durante os últimos anos provocou efeitos prejudiciais relevantes sobre o desempenho macroeconômico, e a fim de capturar isso, Baker, Bloom e Davis (2013) desenvolveram o índice Economic Policy Uncertainty (EPU), apurando que a incerteza política produz efeitos econômicos nas empresas, em relação aos seus investimentos, produção e emprego, principalmente nos setores industriais, que estão mais expostos aos processos políticos e que dependem de recursos do governo (VOTH, 2002; DAÍ; NGO, 2015). 
Colombo (2013) investigou o impacto da incerteza na política econômica dos EUA sobre alguns agregados macroeconômicos da área do Euro, e utilizou para modelagem o índice de incerteza desenvolvido por Baker et al. (2013), em conjunto com demais indicadores alternativos do ciclo de negócios. Os resultados da pesquisa indicaram que o impacto da incerteza provocou uma reação negativa e significativa dos indicadores de preço e quantidade da área do Euro, sugerindo que a contribuição de variações exógenas do indicador de incerteza dos EUA é maior do que a induzida por seu equivalente Europeu.

Nunes e Medeiros (2016) utilizaram o índice EPU para analisar o impacto da incerteza política no mercado de capitais de diversos países - Estados Unidos, Canadá, Reino Unido, Alemanha, Espanha, Itália, França, Índia e China, constatando que houve um aumento no nível de incerteza política a partir do ano de 2008, além de ter sido encontradas evidências de que a incerteza política impacta na volatilidade do mercado, desta forma, quanto pior a situação econômica, maior o impacto da incerteza política na volatilidade das ações.

Nunes (2017), ao analisar os impactos da incerteza política nacional e internacional no mercado acionário brasileiro, constatou um comportamento contracíclico do índice de incerteza política, ou seja, o índice tende a aumentar em situações econômicas desfavoráveis. Quanto ao impacto deste índice no mercado de ações brasileiro, existem evidências de uma relação negativa entre o índice de incerteza política nacional e o retorno de mercado de ações brasileiro e uma relação positiva entre aquele e a volatilidade do mercado.

Fontaine, Didier e Razafindravaosolonirina (2017) analisaram os efeitos da incerteza política e econômica da China, durante os períodos de boom e crise, e concluíram que a atividade econômica dos EUA foi afetada durante o período de crise. No Brasil, além dos reflexos da crise financeira, o processo de impeachment da presidente pode ter elevado o nível de incerteza no ambiente econômico; isso por que a eleição é vista como um fator de incerteza política (BAKER et al., 2015), portanto, mudanças na liderança nacional são capazes de elevar a incerteza e repercutir nos investimentos (JULIO; YOOK, 2012) afetando o desempenho das empresas (BIALKOWSKI et al., 2008; JULIO; YOOK, 2012; PÁSTOR; VERONESI, 2012) e dos mercados financeiros (PÁSTOR; VERONESI, 2013; BROGAARD; DETZEL, 2015).

\section{METODOLOGIA}

Nesta seção é apresentado o percurso metodológico da pesquisa, cujo objetivo é verificar o efeito da incerteza política observada no Brasil sobre o desempenho econômico e a 
valoração das empresas listadas na Bolsa de Valores de São Paulo, atual Brasil Bolsa Balcão B3. Trata-se de uma pesquisa empírica, predominantemente quantitativa e que utilizou métodos de estatística descritiva e inferencial para examinar o objetivo proposto.

\subsection{POPULAÇÃO E AMOSTRA}

A população é composta pelas empresas listadas na B3, já a amostra foi composta pelas empresas que no período de 2011 a 2016 apresentaram dados trimestrais (23 trimestres) disponíveis para determinação das variáveis. Os dados foram coletados por meio da plataforma Bloomberg ${ }^{\circledR}$. A Tabela 1 demonstra como se chegou à amostra de pesquisa.

Tabela 1 - Amostra de pesquisa - observações trimestrais

\begin{tabular}{l|c|c|c|c|c|c|c}
\hline & $\mathbf{2 0 1 1}$ & $\mathbf{2 0 1 2}$ & $\mathbf{2 0 1 3}$ & $\mathbf{2 0 1 4}$ & $\mathbf{2 0 1 5}$ & $\mathbf{2 0 1 6}$ & Total \\
\hline Total de observações por trimestre & 1.636 & 1.572 & 1.652 & 1.724 & 1.708 & 1.254 & 9.546 \\
\hline (-) Companhias financeiras & -272 & -296 & -432 & -488 & -492 & -363 & -2.343 \\
\hline (-) Companhias com PL negativo & -133 & -140 & -133 & -128 & -145 & -122 & -801 \\
\hline (-) Companhias com dados faltantes & -139 & -91 & -64 & -63 & -72 & -51 & -480 \\
\hline (-) Companhias com dados indisponíveis & -288 & -213 & -209 & -201 & -202 & -151 & -1.264 \\
\hline (=) Amostra final (ano) & 804 & 832 & 814 & 844 & 797 & 567 & 4.658 \\
\hline
\end{tabular}

Nota: a linha da Tabela 1 com a descrição "dados indisponíveis” apresenta a quantidade de observações em que não foram apresentados os dados necessários para determinação das variáveis Q de Tobin, Valor de Mercado Adicionado e Price to Book.

Fonte: Dados da pesquisa

A tabela acima detalha a quantidade de empresas que apresentaram as informações trimestrais necessárias para a condução do estudo. Inicialmente foram excluídas as companhias do setor financeiro em razão das diferenças de seus planos de contas em relação às empresas não financeiras. Em seguida foram excluídas as empresas com patrimônio líquido inexistente ou negativo, dadas as distorções que esse saldo contábil poderia gerar na determinação das variáveis que envolvem a rentabilidade das empresas da amostra. Finalmente, foram excluídas as empresas que durante o período não apresentaram saldos contábeis necessários para o cálculo das variáveis de pesquisa.

\subsection{VARIÁVEIS DE PESQUISA}

Considerando que o objetivo do estudo consiste em examinar o impacto da variável independente sobre variáveis de desempenho e de valoração, têm-se dois grupos de variáveis dependentes, o primeiro constituído pelo ROA, ROE, ROI, Ebitda e EVA. No segundo grupo estão as variáveis de valoração, Q de Tobin, MVA e Price to Book. Em ambos os casos, essas variáveis são as comumente utilizadas na literatura que trata de variáveis dessa natureza. 
O ROE corresponde à medida da rentabilidade de uma empresa e demonstra o valor do lucro por ela gerado com os recursos investidos pelos acionistas (DONG; FIRTH; HOU; YANG, 2016). O ROA é um indicador de quão lucrativa uma empresa é em relação ao seu patrimônio total e indica quão eficaz é a gestão ao utilizar seus ativos para gerar lucros (PEREIRA; MARTINS, 2015). O ROI demonstra o desempenho global de uma empresa, pois leva em consideração a alavancagem financeira, ou seja, a representatividade do capital de terceiros sobre a rentabilidade do capital próprio (AGUIAR; PIMENTEL; REZENDE; CORRAR, 2011). O EVA consiste em uma medida usada para determinar se um investimento contribui ou não para a geração de riqueza para os proprietários, medindo a diferença entre o retorno sobre o capital de uma empresa e o custo deste capital (ALMEIDA; VIEIRA NETO; SALLES; SOARES; ESTEVES, 2016). O Ebitda é um indicador do desempenho financeiro de uma empresa, que considera o lucro líquido antes dos juros, impostos, depreciação e amortização adicionados novamente. Em tese pode ser utilizado para analisar e comparar a rentabilidade entre empresas e setores, pois, eliminaria os efeitos de financiamento e decisões contábeis (MOREIRA; JONES; TAVARES; FEHR; SILVA FILHO, 2014).

$\mathrm{O} Q$ de Tobin é um indicador útil para a avaliação de uma empresa, uma vez que representa o valor de mercado desta em relação ao custo de substituição de seus ativos. É baseado na hipótese que, em longo prazo, o valor de mercado de uma empresa deve ser aproximadamente igual ao custo de substituição de seus ativos (PEREIRA; MARTINS, 2015). O MVA corresponde ao indicador obtido por meio do cálculo da diferença entre o valor de mercado da ação e o valor obtido quando se subtrai o capital investido, que são os recursos requeridos para que a empresa possa atingir seus resultados operacionais (FREZATTI, 2007; AGUIAR et al., 2011). O Price to Book é a relação do preço da ação e do valor contábil por ação, utilizado para comparar o valor em bolsa da empresa com o valor contábil dos capitais próprios (GALDI; LOPES, 2011).

A variável independente deste estudo consiste em uma variável dummy temporal, proxy para a incerteza política, cujo objetivo é indicar os trimestres caracterizados como de incerteza política. Assim, ela assume o valor " 1 " a partir do $2^{\circ}$ trimestre de 2014 e vai até o $3^{\circ}$ trimestre de 2016, e valor " 0 " para os outros períodos, sendo identificada pela sigla $D I P_{t}$. A indicação desse período se fundamentou nas informações contidas nos relatórios Global Ratings para América Latina, da $S \& P$, entre março de 2014 e fevereiro de 2016, conforme descrito a seguir.

Em março de 2014 o rating de crédito soberano do Brasil em moeda estrangeira foi 
rebaixado de BBB para BBB- em função da deterioração fiscal do país, dada a capacidade reduzida do governo federal em promover os ajustes fiscais antes das eleições de outubro de 2014. Em julho de 2015 a $S \& P$ alterou a perspectiva de rating de crédito do Brasil em moeda estrangeira e em moeda local de estável para negativa, mas sem mudar a nota de rating soberano. Em setembro de 2015, a agência rebaixou o rating de crédito soberano de BBBpara $\mathrm{BB}+$, colocando o país no subgrupo de grau especulativo, em função do fraco desempenho econômico e implicações das investigações da Operação Lava Jato. Após cinco meses do rebaixamento do rating de crédito soberano, a $S \& P$ novamente promoveu outro corte rebaixando a nota de $\mathrm{BB}+$ para $\mathrm{BB}$, com a manutenção de perspectiva negativa. De acordo com a agência, a trajetória fiscal do país e as necessidades de medidas associadas ao ajuste fiscal tornaram-se quase impossíveis de serem resolvidas considerando o cenário político do momento. Além disso, nos 2014, 2015 e 2016 foram desencadeados diversos efeitos políticos não relatados diretamente nos relatórios da $S \& P$, sobretudo em função da Operação Lava Jato. Tais eventos envolveram desde a prisão de um Senador da República em novembro de 2015, como a coleta de depoimento por condução coercitiva de um expresidente em março de 2016, que se mostraram potencialmente desestabilizadores para a liderança do país por envolver políticos ligados à cúpula do governo, contribuindo para a propagação da instabilidade política no Brasil. Diante do exposto, espera-se que a variável $D I P_{t}$ apresente efeito negativo sobre o desempenho e a valoração das companhias analisadas neste estudo.

Salienta-se novamente que a $D I P_{t}$ é uma proxy e, como tal, apresenta limitações. Tendo em conta o objetivo do estudo, há pelo menos três delas. A primeira, não é possível afirmar que seja a única metodologia disponível para indicação do período de incerteza política no ambiente econômico brasileiro nos anos de 2014, 2015 e 2016. A segunda é que, embora a cobertura de tempo da dummy seja em período próximo ao início da retração econômica no Brasil, seu início (março de 2014) se dá em momento que antecede a sequência de trimestres de retração da economia. A terceira limitação, consequência das demais, é que diante da interseção entre (i) períodos de alertas proferidos pela $S \& P$ a partir 2014 sobre a capacidade reduzida do Poder Executivo em promover ajustes de condução da Política Econômica e (ii) períodos sucessivos de quedas no PIB em 2015 e 2016, não é possível separar com acurácia a fração do período de abrangência da dummy que equivale a incerteza política gerada pela capacidade reduzida do Governo em atuar no front político e o que é efeito da diminuição do ritmo de atividade econômica propriamente dita. Assim, a proxy $D I P_{t}$ 
se mostra como uma aproximação que se baseia em fonte de observação internacional com credibilidade notada por investidores, empresas e reguladores sobre o ambiente econômico brasileiro. Ademais, ressalte-se que a utilidade do relatório Global Ratings da $S \& P$ ultrapassa a função de indicação de downgrades ou upgrades de ratings de crédito corporativos e soberanos. Como evidenciado nesses relatórios, a $S \& P$ também exerce papel de observador internacional de múltiplas vertentes potencialmente capazes de influenciar o ambiente político-econômico de diversos países do mundo. Como forma de atenuar as possíveis limitações expostas para a variável $D I P_{t}$, nas seções 3.4 e 4.4 são descritos e realizados testes de robustez com a utilização de outra proxy empírica para incerteza política.

Em linha com estudos que examinaram a relação do binômio desempenho-valoração e governança corporativa (CARVALHAL-DA-SILVA; LEAL, 2005; SANTOS; SILVEIRA, 2012) e estudos voltados à investigação da qualidade da informação contábil no Brasil (NARDI; NAKAO, 2009; HOLTZ; SARLO NETO, 2014), este estudo utiliza o tamanho das companhias (Size), o nível de endividamento $(L E V)$ e a internacionalização das empresas $(A D R)$ como variáveis de controle, com o objetivo de controlar diferenças entre as companhias que compõe a amostra. A variável Size é determinada pelo valor do logaritmo natural do Ativo Total das companhias ao final de cada trimestre. A variável LEV representa a razão entre o valor total de empréstimos e financiamentos e o Ativo Total das companhias ao final de cada trimestre. Por fim, ADR é uma variável dummy com o valor "1" para as companhias que negociam papéis nos Estados Unidos e "0" para as que não negociam.

Adicionalmente foram incluídas 48 variáveis dummy com o objetivo de controlar características específicas dos setores econômicos das companhias. O critério de classificação utilizado foi o North American Industry Classification System (NAICS) disponível nos sistemas Bloomberg ${ }^{\circledR}$ e Thomson Reuters ${ }^{\circledR}$ para identificação de setores econômicos. Carvalhal-da-Silva e Leal (2005) argumentam que a inclusão de dummies setoriais tem a capacidade de realçar a influência do tipo de atividade empreendida pelo setor sobre a valoração e desempenho da companhia.

\subsection{MÉTODOS}

\subsubsection{Estatística descritiva e análise não-paramétrica}

Esta etapa concentra-se na determinação da média, mediana e desvio padrão das variáveis de pesquisa em dois momentos diferentes: i) Estabilidade Política, período que se inicia no primeiro trimestre de 2011 e vai até o primeiro trimestre de 2014; e ii) Incerteza 
Política, período que começa no segundo trimestre de 2014 e vai até o terceiro trimestre de 2016. Embora a etapa descritiva não produza resultados que possam balizar conclusões, mostra-se capaz de identificar medidas de tendência central e de dispersão e de indicar a direção das variáveis de desempenho e valoração nos dois momentos considerados e se constituem um ponto de partida para a análise inferencial iniciada na etapa não-paramétrica. Tanto as variáveis de desempenho quanto as de valoração mostraram-se distantes de uma distribuição normal e por esse motivo foi aplicada estatística não-paramétrica (FIELD, 2009). Os resultados dos testes de normalidade são apresentados na Tabela 2.

Tabela 2 - Resultados no teste de normalidade para as variáveis de pesquisa

\begin{tabular}{l|c|c|c|c|c|c|c|c}
\hline & ROE & ROA & EVA & EBITDA & ROI & Q & VMA & PTB \\
\hline Estatística teste & 0,182 & 0,102 & 0,161 & 0,173 & 0,225 & 0,212 & 0,205 & 0,268 \\
\hline p-valor & 0,000 & 0,000 & 0,000 & 0,000 & 0,000 & 0,000 & 0,000 & 0,000 \\
\hline Observações & 4.658 & 4.658 & 4.658 & 4.658 & 4.658 & 4.658 & 4.658 & 4.658
\end{tabular}

Nota: O teste de normalidade utilizado foi Kolmorogov-Smirnov. A hipótese nula do teste (H0) é de que os dados seguem distribuição análoga à distribuição normal. Resultados de p-valores abaixo do nível de significância de 5\% evidenciam ausência de normalidade.

O teste Mann-Whitney foi utilizado na análise não-paramétrica para iniciar a etapa inferencial do estudo e examinar diferenças entre as variáveis de desempenho e valoração.

\subsubsection{Análise fatorial}

Considerando a quantidade de variáveis dependentes relacionadas à mensuração da rentabilidade e da valoração das companhias da amostra, analisou-se a viabilidade de aplicação do método da Análise Fatorial Exploratória (AFE), que contemplou as 4.658 observações e resumiu-se nos seguintes passos: i) Exame de adequação para AFE; ii) Análise de Variância Explicada (AVE); e iii) Identificação de fatores.

O exame de adequação para AFE consiste na aplicação da estatística Kaiser-MeyerOlkin (KMO), que compara as correlações simples com as correlações parciais. Os resultados possíveis do KMO transitam entre " 0 " e "1", sendo que valores mais próximos de "1" indicam a aplicabilidade da AFE ao estudo desenvolvido. O resultado da estatística KMO foi 0,800, ou seja, de aplicabilidade boa, conforme intervalos indicados por Fávero, Belfiore, Silva e Chan (2009).

Os resultados da AVE são apresentados na Tabela 3.

Tabela 3 - Analise de variância explicada

\begin{tabular}{c|c|c|c|c|c|c}
\hline \multirow{2}{*}{ Componentes } & \multicolumn{3}{|c|}{ Autovalores iniciais } & \multicolumn{3}{c}{ Soma da Variância Explicada } \\
\cline { 2 - 6 } & Total & $\begin{array}{c}\text { \% de } \\
\text { Variância }\end{array}$ & $\%$ Acumulado & Total & $\begin{array}{c}\text { \% de } \\
\text { Variância }\end{array}$ & \% Acumulado \\
\hline
\end{tabular}




\begin{tabular}{l|c|c|c|c|c|l}
\cline { 2 - 7 } 1 & 4,655 & 58,188 & 58,188 & 3,258 & 40,723 & 40,723 \\
2 & 1,298 & 16,225 & 74,413 & 2,695 & 33,690 & 74,413 \\
3 &, 699 & 8,733 & 83,146 & & & \\
4 &, 523 & 6,535 & 89,681 & & & \\
5 &, 360 & 4,496 & 94,177 & & & \\
6 &, 320 & 3,996 & 98,173 & & & \\
7 &, 137 & 1,713 & 99,887 & & & \\
8 &, 009 &, 113 & 100,000 & & & \\
\hline
\end{tabular}

Embora não sejam estabelecidos parâmetros de máximo e mínimo de variância explicada em percentuais e nem máximo e mínimo para o número de fatores extraídos, podese observar que 2 fatores explicam 74,41\% da variabilidade das 8 variáveis dependentes.

$\mathrm{Na}$ etapa de identificação de fatores ocorreu a análise da Matriz de Componentes Rotacionados, com o objetivo de identificar quais variáveis pertencem a cada um dos dois fatores extraídos. A Tabela 4 apresenta o resultado da identificação dos fatores.

Tabela 4 - Matriz de componentes rotacionados

\begin{tabular}{c|c|c}
\hline \multirow{2}{*}{ Variáveis } & \multicolumn{2}{|c}{ Componentes } \\
\cline { 2 - 3 } Q & Fator 1 & Fator 2 \\
VMA &, 924 & - \\
PTB &, 919 & - \\
ROE &, 848 & - \\
ROA & - &, 806 \\
ROI & - &, 869 \\
EVA & - &, 665 \\
EBITDA & - &, 828 \\
\hline Variância Explicada & - &, 703 \\
\hline
\end{tabular}

Os resultados da matriz de componentes rotacionados evidenciam que as cargas fatoriais das variáveis de valoração (Q, VMA e PTB) formaram um fator em separado das variáveis de desempenho econômico (ROE, ROA, ROI, EVA e Ebitda). O Fator 1 e o Fator 2 apresentaram variância explicada de 33,69\% e 40,72\%, respectivamente. Tendo em vista que as características das variáveis formaram fatores que são coerentes com a natureza do que se propõem a mensurar, convencionou-se denominar o Fator 1 de "Fator de Valoração (FV)" e o Fator 2 de "Fator de Desempenho (FD)".

Fávero et al. (2009) observaram que, ao permitir que um conjunto de variáveis seja transformado em fatores, os escores fatoriais gerados pela AFE podem ser utilizados como entrada para outras técnicas multivariadas, dentre elas a regressão múltipla. Considerando que o objetivo do estudo é examinar o efeito do período de incerteza política $\left(D I P_{t}\right)$ sobre o desempenho e valoração das companhias, ao invés de se observar tal reflexo sobre cada uma das sete variáveis dependentes, o efeito foi verificado sobre os dois fatores extraídos da AFE. (c) (1) \& REAd | Porto Alegre - Vol. 25 - N. ${ }^{\circ} 3$ - Setembro / Dezembro 2019 - p. 96 - 123 


\subsubsection{Análise de regressão com dados em painel e teste de hipóteses}

Considerando que as empresas que compõe a amostra estão empilhadas em uma base de dados que considera o valor das variáveis de pesquisa em uma série de 23 trimestres, tratase de uma estrutura de dados em painel. Nessa direção, este estudo propõe-se em examinar o efeito da incerteza política por meio dos modelos de regressão linear múltipla a seguir:

$$
\begin{aligned}
& F V_{i t}=\beta_{0}+\beta_{1} D I P_{t}+\beta_{2} E n d_{i t}+\beta_{3} \operatorname{Tam}_{i t}+\beta_{4} A D R_{i t}+\gamma_{i}+e_{i t}(\text { modelo } 1) \\
& F D_{i t}=\beta_{0}+\beta_{1} D I P_{t}+\beta_{2} E n d_{i t}+\beta_{3} \operatorname{Tam}_{i t}+\beta_{4} A D R_{i t}+\gamma_{i}+e_{i t}(\text { modelo } 2)
\end{aligned}
$$

Em que $F V_{i t}$ representa o fator de valoração da empresa $i$ no trimestre $t ; D I P_{t}$ representa dummy com valor "1" para período de incerteza e "0" para o contrário; $E n d_{i t}$ representa o nível de endividamento da empresa $i$ no trimestre $t$; $\operatorname{Tam}_{i t}$ representa o porte da empresa $i$ no trimestre $t ; A D R_{i t}$ representa dummy com valor "1" para emissora de ADR e " 0 " para o contrário; $F D_{i t}$ representa o fator de desempenho da empresa $i$ no trimestre $t ; \gamma_{i}$ representa as dummies setoriais; e $\beta_{0}$ representa o intercepto dos modelos.

Considera-se que o período de incerteza política $\left(D I P_{t}\right)$ tenha exercido efeito negativo sobre o desempenho econômico e valoração das empresas pesquisadas, e por esse motivo, espera-se que no Modelo 1 e no Modelo 2 o coeficiente $\beta_{1}$ seja negativo. Nessa direção, os testes de hipóteses para esses coeficientes são $\mathrm{H}_{0}: \beta_{1} \geq 0$ e $\mathrm{H}_{1}: \beta_{1}<0$

Deve-se observar que durante a computação das regressões foram feitos testes de hipóteses ligados à identificação do desempenho dos interceptos dos Modelos 1 e 2 . Inicialmente testou-se a hipótese de os modelos serem POLS (Pooled Ordinary Least Squares), e em seguida aplicou-se o teste de Chow para verificar a presença de efeitos fixos, e finalmente foi examinada a hipótese de se tratar de modelos com efeitos aleatórios.

\subsection{ROBUSTEZ DE RESULTADOS}

Com o objetivo de examinar a robustez dos resultados das estimações dos modelos de valoração e de desempenho apresentados na subseção 2.3.3, a variável dummy $\left(D I P_{t}\right)$ será substituída pela variável descrita como Economic Policy Uncertainty Index (EPU), desenvolvida por Baker et al. (2013). O EPU Index é uma medida que objetiva quantificar a intensidade da incerteza política presente na economia brasileira, tendo sido construída a partir de textos do periódico Jornal Folha de São Paulo que tenham em seu conteúdo termos como "incerto", “incerteza", "econômico" e "economia”. Nesta substituição, a variável EPU será incorporada à análise de dados da pesquisa considerando o mesmo marco temporal utilizado para construção da variável dummy $D I P_{t}$. 
O EPU Index está disponível para 25 países, Brasil incluso, cujos dados são apresentados mensalmente e, portanto, podem ser observados trimestralmente. Trata-se de uma proxy para incerteza política empregada em pesquisas nacionais e estrangeiras. Como exemplo, têm-se investigações voltadas a relacionar a incerteza política dos EUA e a propagação de seus efeitos na Europa (COLOMBO, 2013); incerteza política e o mercado acionário sob a lente de seleções de medidas tomadas por Governos (PÁSTOR; VERONESI, 2013); a incerteza política e a valoração de ativos, além do mercado de ações (BROGAARD; DETZEL, 2015); e a incerteza política e o prêmio pelo risco em diversos países (NUNES; MEDEIROS, 2016).

\section{RESULTADOS}

\subsection{ESTATÍSTICA DESCRITIVA}

Na tabela 5 são apresentados os resultados das estatísticas descritivas das variáveis de pesquisa para os dois períodos analisados no estudo.

Tabela 5 - Estatísticas descritivas

\begin{tabular}{c|c|c|c|c|c|c}
\hline \multirow{2}{*}{} & \multicolumn{3}{|c|}{ Estabilidade Política } & \multicolumn{3}{c}{ Incerteza Política } \\
\cline { 2 - 7 } & Média & Mediana & Desvio Padrão & Média & Mediana & Desvio Padrão \\
\hline ROE & $7,50 \%$ & $8,76 \%$ & $31,82 \%$ & $3,12 \%$ & $6,34 \%$ & $32,46 \%$ \\
\hline ROA & $3,99 \%$ & $3,72 \%$ & $8,90 \%$ & $2,31 \%$ & $2,35 \%$ & $8,96 \%$ \\
\hline ROI & $9,63 \%$ & $8,66 \%$ & $27,16 \%$ & $6,25 \%$ & $5,97 \%$ & $15,61 \%$ \\
\hline EVA & $-4,96 \%$ & $-4,97 \%$ & $9,14 \%$ & $-7,15 \%$ & $-6,56 \%$ & $16,86 \%$ \\
\hline EBITDA & $2,40 \%$ & $2,37 \%$ & $4,86 \%$ & $2,08 \%$ & $2,13 \%$ & $3,48 \%$ \\
\hline Q & 1,46 & 1,16 & 1,02 & 1,26 & 1,02 & 0,76 \\
\hline VMA & 0,34 & 0,03 & 1,00 & 0,12 & $-0,09$ & 0,74 \\
\hline PTB & 2,43 & 1,43 & 3,69 & 2,04 & 1,09 & 3,53 \\
\hline Observações & 2.668 & 2.668 & 2.668 & 1.990 & 1.990 & 1.990 \\
\hline
\end{tabular}

Nota: Estabilidade política compreende o período do primeiro trimestre/2011 ao primeiro trimestre/2014. Instabilidade política compreende o período que vai do segundo trimestre/2014 até o terceiro trimestre/2016.

Ao considerar as variáveis que mensuram o desempenho econômico, a Tabela 5 evidencia que todas apresentaram queda nominal de média e mediana quando se comparam os dois períodos. Embora as variáveis ROE, ROA e ROI se mantiveram positivas em termos de média, as quedas nominais foram de 58,39\%, 42,09\% e 35,10\%, respectivamente, no período de incerteza política. $\mathrm{Na}$ variável Ebitda, ainda que descritivamente, observa-se queda menos intensa, com redução de $2,40 \%$ em média no período estabilidade para 2,08\% no período de incerteza política. No caso especifico do EVA, este já apresentava valor negativo no período anterior ao da instabilidade política. No entanto, ao considerar esse período, seu valor passou $4,96 \%$ para $-7,15 \%$ indicando piora nominal de $44,20 \%$.

(c) $(1) \Theta 2$ REAd | Porto Alegre - Vol. 25 - N..$^{\circ} 3$ - Setembro / Dezembro 2019 - p. 96 - 123 
Para as variáveis de valoração, a tendência é a mesma. A Tabela 5 mostra queda de 64,44\% da média do MVA entre os dois períodos. Apesar dessa indicação não permitir inferências ou até mesmo comparações, sugere-se que durante o período de incerteza política houve forte perda de valor de mercado das empresas ante ao valor investido.

De modo geral, a Tabela 5 mostra que a direção de todas as medidas de desempenho e valoração foi de limitação da capacidade das companhias brasileiras em produzir resultados crescentes, provocando deterioração em seus valores de mercado.

\subsection{TESTES NÃO-PARAMÉTRICOS}

A Tabela 6 apresenta o resultado da aplicação dos testes não paramétricos para as variáveis de pesquisa.

Tabela 6 - Resultados dos testes não paramétricos

\begin{tabular}{c|c|c}
\hline Variáveis de Pesquisa & Diferença & $\mathbf{Z}$ \\
\hline ROE & $-2,418 \%$ & $-6,30^{* * *}$ \\
\hline ROA & $-1,371 \%$ & $-7,06^{* * *}$ \\
\hline ROI & $-2,691 \%$ & $-11,59^{* * *}$ \\
\hline EVA & $-1,585 \%$ & $-7,88^{* * *}$ \\
\hline EBITDA & $-0,239 \%$ & $-5,09^{* * *}$ \\
\hline Q & $-0,1367$ & $-10,87^{* * *}$ \\
\hline VMA & $-0,1261$ & $-11,53^{* * *}$ \\
\hline PTB & $-0,3486$ & $-10,80^{* * *}$
\end{tabular}

Nota: $* * *, * *$ e $*$ indicam significância estatística ao nível $1 \%, 5 \%$ e $10 \%$, respectivamente. Hipótese nula $\left(\mathbf{H}_{0}\right)$ : medianas iguais para os dois períodos. Diferença: indica a diferença de mediadas entre o período de Estabilidade Política e Incerteza Política.

Ao nível de 1\% de significância, rejeitou-se a hipótese nula de igualdade de medianas ao considerar os dois períodos. Torna-se possível observar que, tanto as variáveis de desempenho quanto as de valoração são estatisticamente diferentes (e menores) durante o período de incerteza política. Este teste dá indícios que auxiliam a fundamentação de que o período que se inicia no primeiro trimestre de 2014 e vai até o terceiro trimestre de 2016 mostrou declínio do desempenho das empresas ligado ao momento político do país. Reforça também a ideia de uma potencial diferenciação dos períodos em termos de exame e do impacto negativo sobre variáveis financeiras e contábeis das empresas amostradas, constatação esta que será ampliada na etapa de análise multivariada dos dados.

\subsection{ANÁLISE MULTIVARIADA}

Esta fase tem o objetivo de examinar o poder explicativo da variável $D I P_{t}$ sobre o 
Fator de Valoração $\left(F V_{i t}\right)$ e sobre o Fator de Desempenho $\left(F D_{i t}\right)$, por meio dos Modelos 1 e 2 , respectivamente. Esse exame é efetuado por meio da computação das regressões múltiplas com dados em painel. Na Tabela 7são apresentados os resultados das regressões do Modelo 1 (Fator de Valoração).

Tabela 7 - Resultados da regressão linear múltipla para o Modelo 1 - Fator de Valoração

\begin{tabular}{c|c|c|c}
\hline & $(\mathbf{1})$ & $\mathbf{( 2 )}$ & $\mathbf{( 3 )}$ \\
\hline \multirow{2}{*}{ Intercepto } & 0,270 & $-0,260$ & $5,745^{* * *}$ \\
& {$[0,322]$} & {$[0,445]$} & {$[0,310]$} \\
\hline \multirow{2}{*}{$D I P_{t}$} & $-0,186^{* * *}$ & $-0,191^{* * *}$ & $-0,067^{* * *}$ \\
& {$[0,051]$} & {$[0,051]$} & {$[0,018]$} \\
\hline \multirow{2}{*}{$T A M_{i t}$} & $-0,011$ & 0,019 & $-0,709^{* * *}$ \\
& {$[0,044]$} & {$[0,054]$} & $0,038]$ \\
\hline \multirow{2}{*}{$L E V_{i t}$} & $-0,316$ & $-0,263$ & {$[0,140]$} \\
\hline \multirow{2}{*}{$A D R_{i t}$} & {$[0,455]$} & $-0,003$ & 0,001 \\
\hline Observações & 0,020 & {$[0,151]$} & 0,043 \\
\hline$R^{2}$ & {$[0,158]$} & 4658 & 4658 \\
\hline Efeitos Fixos & 4658 & $31,23 \%$ & $79,06 \%$ \\
\hline
\end{tabular}

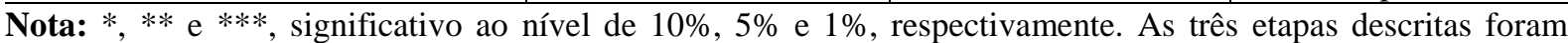
computadas com Erros-Padrão Robustos em relação à heterocesdasticidade e autocorrelação. Etapa 2: considera as dummies setoriais. Etapa 3: resultado da aplicação do teste de Chow para diferença de interceptos e especificação de Hausman com resultados $\chi^{2}=51,0461 * * *$ e $\chi^{2}=165,129 * * *$, respectivamente, sendo decidido pela especificação de um modelo de efeitos fixos. Valores calculados para VIF (Variance Inflaction Factor) variaram entre 1,110 e 1,138

A tabela 7 mostra o efeito significativo da variável representativa da incerteza política $D I P_{t}$ para as três etapas do Modelo 1. Os resultados indicam que o período indicado como o de presença de incerteza política no Brasil provocou efeito de deterioração do valor de mercado das empresas brasileiras. Tais resultados se mantêm mesmo após o controle setorial da amostra (etapa 2), com $1 \%$ de significância, e após a verificação dos efeitos fixos por empresas (etapa 3). Deve-se observar que durante a condução dos resultados, foi aplicada, linha a linha da base de dados, o teste de hipótese para a verificação de presença de outliers multivariados, por meio da distância de Mahalanobis. Ao nível de $1 \%$, os escores $\chi^{2}$ mostraram-se dentro da área de aceitação da hipótese nula de ausência de outliers, logo, os resultados não estão alavancados pela presença de outliers multivariados.

A Tabela 8 apresenta os resultados da estimação dos coeficientes das regressões para o Modelo 2 (Fator de Desempenho).

Tabela 8 - Resultados da regressão linear múltipla para o Modelo 2 - Fator de Desempenho

\begin{tabular}{c|c|c|c}
\hline & $\mathbf{( 1 )}$ & $\mathbf{( 2 )}$ & $\mathbf{( 3 )}$ \\
\hline Intercepto & 0,038 & 0,186 & $-4,037$
\end{tabular}




\begin{tabular}{c|c|c|c} 
& {$[0,321]$} & {$[0,389]$} & {$[2,548]$} \\
\hline \multirow{2}{*}{$D I P_{t}$} & $-0,312^{* * *}$ & $-0,310^{* * *}$ & $-0,386^{* * *}$ \\
& {$[0,059]$} & {$[0,059]$} & {$[0,101]$} \\
\hline \multirow{2}{*}{$T A M_{i t}$} & $0,074^{*}$ & 0,075 & $0,607^{*}$ \\
& {$[0,039]$} & {$[0,046]$} & {$[0,314]$} \\
\hline \multirow{2}{*}{$L E V_{i t}$} & $-1,424^{* * *}$ & $-1,390^{* * *}$ & $-2,987 * * *$ \\
& {$[0,299]$} & {$[0,287]$} & $0,582]$ \\
\hline \multirow{2}{*}{$A D R_{i t}$} & $-0,269 * *$ & $-0,288^{* *}$ & 0,014 \\
\hline Observações & {$[0,109]$} & {$[0,111]$} & 4658 \\
\hline$R^{2}$ & 4658 & 4658 & $57,31 \%$ \\
\hline Efeitos Fixos & $9,43 \%$ & $11,97 \%$ & Empresas
\end{tabular}

Nota: *, ** e $\mathrm{e}^{* * *}$, significativo ao nível de $10 \%, 5 \%$ e $1 \%$, respectivamente. As três etapas descritas foram computadas com Erros-Padrão Robustos em relação à heterocesdasticidade e autocorrelação. Etapa 2: considera as dummies setoriais. Etapa 3: resultado da aplicação do teste de Chow para diferença de interceptos e especificação de Hausman com resultados $\chi^{2}=15,4122^{* * *}$ e $\chi^{2}=58,8474 * * *$, respectivamente, sendo decidido pela especificação de um modelo de efeitos fixos. Valores calculados para VIF (Variance Inflaction Factor) variaram entre 1,113 e 1,141 .

A Tabela 8 indica que para o fator de desempenho a dummy $D I P_{t}$ mostrou-se relevante e com o sinal dentro do esperado. Ao nível de $1 \%$ de significância estatística, para todas as três etapas de computação das regressões múltiplas, o período de incerteza política apresentou reflexo negativo para o desempenho das companhias. Tais resultados sugerem que a incerteza observada no país durante o período foi capaz de se materializar em resultados contábeis substancialmente mais fracos para as empresas brasileiras. Os resultados foram transcritos após a realização de testes para a presença de outliers multivariados.

Embora o estudo de Nunes e Medeiros (2016) tenha-se concentrado em países da Ásia, América do Norte e Europa, as constatações de influência negativa sobre empresas brasileiras vão ao encontro dos achados daqueles autores que também constataram ligação negativa entre incerteza política e o mercado de capitais. Em posição assemelhada, os achados deste estudo corroboram a pesquisa de Nunes (2017) que do mesmo modo observaram relação inversa entre a incerteza política e o mercado acionário.

\subsection{TESTES DE ROBUSTEZ}

O objetivo desta seção é apresentar os resultados da análise univariada e multivariada determinados com o emprego da variável EPU Index, levando em conta os períodos considerados como de Estabilidade Política e Instabilidade Política nesse estudo. A Tabela 9 mostra a estatística descritiva e a inferência univariada para a variável.

Tabela 9 - Estatísticas descritivas para a variável EPU (Economic Policy Uncertainty)

\begin{tabular}{l|r} 
Estabilidade Política & Incerteza Política
\end{tabular}




\begin{tabular}{c|c|c|c|c|c|c|c}
\multicolumn{2}{r|}{ Média } & Mediana & D. Padrão & Média & Mediana & D. Padrão & \\
\hline EPU & 151,60 & 154,30 & 50,20 & 263,30 & 272,25 & 125,70 & $-2,652^{* * *}$ \\
\hline Ln_EPU & 4,97 & 5,04 & 0,35 & 5,44 & 5,60 & 0,58 & $-2,269 * *$ \\
\hline
\end{tabular}

Nota: considerando a hipótese nula de presença de normalidade, foi aplicado o teste Shapiro-Wilk para a variável EPU e para sua forma logarítmica (Ln_EPU), tendo sido observados p-valores de 0,0312 e 0,7065, respectivamente. Esses resultados possibilitaram a aplicação do teste t para examinar a diferença de médias da variável EPU e Ln_EPU nos períodos considerados de Estabilidade Política e Incerteza Política. Os p-valores associados aos resultados dos testes t com resultados de $-2,652$ e $-2,269$ são 0,0222 e 0,0398 , respectivamente.

Mostra-se na Tabela 9 que para a cobertura de tempo considerada como período de Estabilidade Política, a média do EPU Index foi de 151,60 pontos, associado a coeficiente de variação de 32,53\% (50,20/154,30). Para o período de incerteza política, vê-se aumento pronunciado do EPU em mais de $76 \%$ e também acompanhado do aumento da dispersão com coeficiente de variação de 46,17\% $(125,70 / 263,30)$.

Ao nível crítico de $1 \%$ e 5\%, a Tabela 9 também evidencia existir diferença estatisticamente significativa para a variável EPU no interregno examinado. Os p-valores calculados para a variável e para sua forma logarítmica (Ln_EPU) se mostraram significativos, o que sugere convergência na interpretação de resultados entre a variável EPU e a variável dummy de incerteza política (DIPt) obtida a partir do relatório Global Ratings da $S \& P$, ainda que restrita à inferência univariada.

A Tabela 10 apresenta a análise multivariada para os modelos de Valoração e de Desempenho (3 e 4) considerando a variável EPUt em substituição à variável DIPt.

Tabela 10 - Resultados da regressão linear múltipla para os Modelos 1 e 2 - Fator de Valoração e Fator de Desempenho

\begin{tabular}{c|c|c|c|c}
\hline \multirow{2}{*}{} & \multicolumn{2}{|c|}{ Fator de Valoração } & \multicolumn{2}{c}{ Fator de Desempenho } \\
\cline { 2 - 5 } & $\mathbf{( 1 )}$ & $\mathbf{( 2 )}$ & $\mathbf{( 3 )}$ & $\mathbf{( 4 )}$ \\
\hline \multirow{2}{*}{ Intercepto } & 0,528 & $6,432 * * *$ & $-0,172$ & $-3,612^{* *}$ \\
& $(0,368)$ & $(1,220)$ & $(0,398)$ & $(1,795)$ \\
\hline \multirow{2}{*}{$E P U_{t}$} & $-0,177 * * *$ & $-0,092^{* * *}$ & $-0,131^{* * *}$ & $-0,190 * * *$ \\
& $(0,031)$ & $(0,022)$ & $(0,036)$ & $0,044)$ \\
\hline \multirow{2}{*}{$T A M_{i t}$} & 0,011 & $-0,760 * * *$ & $0,150 * * *$ & $(0,245)$ \\
\hline \multirow{2}{*}{$L E V_{i t}$} & $(0,050)$ & $(0,156)$ & $(0,044)$ & $3,162^{* * *}$ \\
& $-0,263$ & $-0,744 * *$ & $1,616 * * *$ & $(0,485)$ \\
\hline \multirow{2}{*}{$A D R_{i t}$} & $(0,335)$ & $(0,315)$ & $(0,272)$ & $0,208^{* *}$ \\
& 0,049 & 0,052 & $0,205^{* *}$ & $(0,099)$ \\
\hline Observações & $(0,140)$ & $(0,037)$ & $(0,103)$ & 4.658 \\
\hline$R^{2}$ & 4.658 & 4.658 & 4.658 & $10,74 \%$ \\
\hline Efeitos Fixos & $34,72 \%$ & $15,54 \%$ & $21,49 \%$ & Empresas \\
\hline
\end{tabular}

Nota: *,** e ***, significativo ao nível de $10 \%, 5 \%$ e $1 \%$, respectivamente. As quatro etapas descritas foram computadas com Erros-Padrão Robustos em relação à heterocesdasticidade e autocorrelação. Regressões 1 e 3: considera dummies setoriais. Regressões 2 e 4: resultado da aplicação do teste de Chow para diferença de interceptos e especificação de Hausman com resultados $\chi^{2}=27,043 * * *$ e $\chi^{2}=113,96 * * *$, respectivamente, sendo decidido pela especificação de modelos de efeitos fixos. Valores calculados para VIF (Variance Inflaction Factor) variaram entre 1,119 e 1,183 nos quatro modelos. Valores entre parênteses são erros-padrão associados às estimações dos coeficientes. 
Ao nível de significância de 1\%, os resultados apresentados na Tabela 10 são semelhantes àqueles mostrados nas Tabelas 7 e 8 ao evidenciar o efeito negativo da incerteza política tanto sobre a valoração (colunas 1 e 2) quanto sobre o desempenho (colunas 3 e 4 ) de corporações brasileiras. A Tabela 10 mostra que os coeficientes estimados para a variável EPU apresentam a mesma direção e semelhante magnitude dos parâmetros estimados a partir da variável dummy de incerteza política construída a partir do relatório Global Ratings da $S \& P$. Semelhante ao conteúdo evidenciado nas Tabelas 7 e 8 , os modelos de valoração e de desempenho presentes na Tabela 10 se mostraram persistentes em termos de consistência de resultados mesmo após a introdução de variáveis de controle e efeitos fixos de setores econômicos e de empresas. Com pronunciada robustez empírica, os resultados apresentados nesta seção reiteram que a incerteza política propagada na economia é capaz de destruir valor e reduzir a performance econômico-financeira das corporações.

\section{CONCLUSÃO}

A partir de 2014 o cenário econômico do Brasil passou a ser influenciado por uma incerteza política. Além disso, o desempenho ruim da economia e indícios relacionados às práticas de corrupção alcançou proporções elevadas, com reflexos sobre a própria capacidade do governo em conduzir os rumos da economia. Para Julio e Yook (2012) a essência da incerteza política está relacionada em como os governantes irão modelar políticas para estimular o nível de investimento privado.

Tendo como amostra as empresas brasileiras listadas na B3, este estudo permitiu inferir que elas não passaram intactas a esse período. Diante de um cenário de economia menos influente e prejudicado pelos reflexos da incerteza política, percebeu-se que esta combinação se propagou ao mercado real impactando negativamente as empresas em sua capacidade de gerar resultados e na valoração dos seus ativos. Tais resultados guardam semelhança com os estudos desenvolvidos por Baker et al. (2015) e Julio e Yook (2012).

É possível constatar que em 2014 (antes mesmo de o país entrar em recessão técnica a partir de 2015 - dois períodos trimestrais de queda do PIB seguidos), a capacidade de geração de lucros das empresas já estava em queda. Isso pode ser evidenciado pelo resultado negativo e materialmente relevante da variável dummy $D I P_{\mathrm{t}}$ proposta no estudo, sugerindo que, mesmo antes de 2015 e 2016, foi possível observar o desaquecimento de desempenho e a destruição 
do valor de mercado das companhias que compõem este estudo. As mesmas constatações são feitas quando se considera a variável EPU, utilizada nos testes de robustez desta pesquisa. Com efeito, essa pesquisa indica que as perdas de oportunidades de negócios para essas companhias podem ter começado antes da economia entrar efetivamente em recessão, o que seria indício de antecipação, por parte das companhias, dos reflexos vindouros de incerteza política e economia mais fraca.

As constatações mostradas neste estudo são indícios que sustentam a ideia de que perdas de oportunidades de rentabilidade e de valoração corporativas influenciadas por ações e decisões de Governos representam custos para o funcionamento eficiente do sistema econômico, conforme argumenta Williamson (1985). Considerando que decisões de Política Econômica são fonte de incerteza (Julio e Yook, 2012), as evidências dessa pesquisa corroboram as reflexões de North (1992) de que Governos podem criar custos de transação para as corporações. E, à medida que se propagam decisões de Governo que negligenciam a criação de ambiente econômico em que investidores possam maximizar sua utilidade, conforme defendido por Pástor e Veronsi (2013), observa-se queda de lucro e destruição de valor como resultante dessa omissão.

Esses achados devem ser interpretados à luz das seguintes limitações: (i) outras variáveis podem capturar o período de incerteza política; (ii) o período de alcance da dummy incerteza política antecedeu a sequência de trimestres de retração da economia; e (iii) diante da convergência entre os períodos relatados pela $S \& P$ sobre a condução da política econômica e os períodos sucessivos de quedas do PIB, não é possível identificar com precisão a fração do período que representa a incerteza política.

Como desdobramentos futuros desta pesquisa, pode-se verificar o impacto de outras variáveis que possam representar a incerteza política sobre o desempenho e a valoração de empresas brasileiras e estrangeiras, sobretudo de países da América Latina e de países emergentes de outros continentes. Outra possibilidade consiste em verificar o efeito da incerteza política sobre vertentes além do desempenho e valoração, como por exemplo, as decisões de investimento ou de postergação de investimentos das corporações, podendo, nesse caso, o Capex (Capital Expenditures) ser utilizado como proxy para as decisões de investimento. Por fim, a abordagem metodológica metodologia utilizada neste estudo pode ser aplicada às empresas de capital fechado, tendo em vista a disponibilidade no Brasil de bases de dados (Compustat e Capital I.Q.) que incluem essas empresas. 


\section{REFERÊNCIAS}

AGUiAR, A. B.; PIMENTEL, R. C.; REZENDE, A. J.; CORRAR, L. J. Análise dos direcionadores de valor em empresas brasileiras. Revista de Administração Mackenzie, v. 12, n. 2, p. 90-112. 2011. DOI: http://dx.doi.org/10.1590/S1678-69712011000200005

ALMEIDA, L. S. F.; VIEIRA NETO, J.; SALLES, M. T.; SOARES, C. A. P.; ESEVES, Y. O. Análise comparativa entre o $\mathrm{EVA}^{\circledR} \mathrm{e}$ os indicadores financeiros (contábeis) tradicionais de empresas da construção civil brasileira: um estudo documental. Gestão e Produção, v. 23, n. 4, p. 733-756, 2016. DOI: http://dx.doi.org/10.1590/0104-530x1722-15

BAKER, S. R.; BLOOM, N.; DAVIS, S. J. Measuring economic policy uncertainty. Working paper, 2013.

BAKER, S. R.; BLOOM, N.; DAVIS, S. J. Measuring economic policy uncertainty. NBER Working Paper n. 21633, p.1-75, 2015.

BAKER, S. R.; BLOOM, N.; DAVIS, S. J. Measuring economic policy uncertainty. The Quarterly Journal of Economics, v. 131, n. 4, p. 1593-1636, 2016. DOI: https://doi.org/10.1093/qje/qjw024

BARKER, R.; PENMAN, S. Moving the Conceptual Framework Forward: Accounting for Uncertainty. Unpublished paper, Oxford University and Columbia University, 2016.

BERNANKE, B. S. Irreversibility, Uncertainty, and Cyclical Investment. The Quarterly Journal of Economics, v. 97, n. 1, p. 85-106, 1983. DOI: 10.3386/w0502.

BIALKOWSKI, J.; GOTTSCHALK, K.; WISNIEWSKI, T. P. Stock market volatility around national elections. Journal of Banking and Finance, v. 32, p. 1941-1953, 2008. DOI: https://doi.org/10.1016/j.jbankfin.2007.12.021

BROGAARD, J.; DETZEL, A. The Asset-Pricing Implications of Government Economic Policy Uncertainty. Management Science, v. 61, n. 1, p. 3-18, 2015. DOI: https://doi.org/10.1287/mnsc.2014.2044

BU, D.; HU, F.; LIN, P. T.; ZHANG, C. Political uncertainty, institutions, and accounting conservatism: Evidence from the provincial official turnover in China. Working paper, Hong Kong Polytechnic University, 2015.

CARVALHAL-DA-SILVA, A. L.; LEAL, R. P. Corporate governance index, firm valuation and performance in Brazil. Revista Brasileira de Finanças, v. 3. n. 1, p. 1-18, 2005.

COLOMBO, V. Economic policy uncertainty in the US: Does it matter for the Euro area? Economics Letters, v. 121, p. 39-42, 2013. DOI: https://doi.org/10.1016/j.econlet.2013.06.024

COSTA FILHO, A. E. Incerteza e atividade econômica no Brasil. Economia Aplicada, v. 18, n. 3, p. 421-453, 2014. DOI: http://dx.doi.org/10.1590/1413-8050/ea607

DAVIDSON, P. Is probability theory relevant for uncertainty? A post Keynesian perspective. (c) (1) @ REAd | Porto Alegre - Vol. 25 - N. ${ }^{\circ} 3$ - Setembro / Dezembro 2019 - p. 96 - 123 
Journal of Economics Perspectives, v. 5, n. 1, p. 129-143, 1991. DOI: 10.1257/jep.5.1.129

DAI, L.; NGO, P. Political Uncertainty and Accounting Conservatism. Working paper, Australian National University, p. 1-47, 2015.

DE PAULA, Luiz Fernando. O recente boom de crédito. Valor Econômico, São Paulo, 28 jul. 2011. Disponível em: http://www.valor.com.br/opiniao/202809/o-recente-boom-decredito. Acesso em: 10 jan. 2017.

DONG, Y., FIRTH, M., HOU, W., \& YANG, W. Evaluating the performance of Chinese commercial banks: A comparative analysis of different types of banks. European Journal of Operation Research, v. 252, p. 280-295, 2016. DOI: https://doi.org/10.1016/j.ejor.2015.12.038

FÁVERO, L. P.; BELFIORE, P.; SILVA, F. L.; CHAN, B. L. Análise de dados: modelagem multivariada para tomada de decisões. Rio de Janeiro: Elsevier, 2009.

FIELD, A. Descobrindo a estatística usando o SPSS-2. Bookman Editora, 2009.

FONTAINE, I.; DIDIER, L.; RAZAFINDRAVAOSOLONIRINA, J. Foreign policy uncertainty shocks and US macroeconomic activity: Evidence from China. Economics Letters, v. 155, p. 121-125, 2017. DOI: https://doi.org/10.1016/j.econlet.2017.03.034

FREZATTI, F. The "economic paradigm" in management accounting: return on equity and the use of various management accounting artifacts in a Brazilian context. Managerial Auditing Journal, v. 22, n. 5, p. 514-532, $2007 . \quad$ DOI: https://doi.org/10.1108/02686900710750784

GALDI, F. C.; LOPES, R. F. Avaliação de ações e números contábeis: aplicação dos modelos Zhang (2000) e Zhang \& Chen (2007) no mercado brasileiro. Revista Brasileira de Finanças, v. 9, n. 1, p. 131-157, 2011.

GALLON, A. V.; SALAMONI, F. L.; CASTRO NETO, J. L.; BEUREN, I. M. Utilização do método do valor presente dos fluxos de caixa futuros na avaliação de ativos em condições de certeza e incerteza. Revista UnB, v. 11, n. 1-2, p. 296-311, 2008.

GULATI, R.; NOHRIA, N.; WOHLGEZOGEN, F. Roaring out of recession. Harvard Business Review, v. 88, n. 3, p. 62-69, 2010.

HENDRIKSEN, E. S.; VAN BREDA, M. F. Teoria da contabilidade. 5. ed. São Paulo: Atlas, 1999.

HOLTZ, L.; SARLO NETO, A. Efeitos das Características do Conselho de Administração sobre a Qualidade da Informação Contábil no Brasil. Revista Contabilidade \& Finanças, v. 25, n. 66, p. 255-266, 2014. DOI: https://doi.org/10.1590/1808-057x201412010

JULIO, B.; YOOK, Y. Political Uncertainty and Corporate Investment Cycles. The Journal of Finance, v. 67, n. 1, p. 45-83, 2012. DOI: https://doi.org/10.1111/j.1540-6261.2011.01707

KEYNES, J. M. The General Theory of Employment. The Quarterly Journal of Economics, v. 51, n. 2, p. 209-223, 1937.

(c) $(1)(9)$ REAd | Porto Alegre - Vol. 25 - N. ${ }^{\circ} 3$ - Setembro / Dezembro 2019 - p. 96 - 123 
KEYNES, J. M. A Teoria Geral do Emprego, do Juro e da Moeda. São Paulo: Nova Cultural, 1996.

LEAHY, Joe. Economia brasileira se dá bem em meio à insensatez global. Valor Econômico, São Paulo, 04 ago. 2011. Disponível em: http://www.valor.com.br/brasil/972106/economiabrasileira-se-da-bem-em-meio-insensatez-global. Acesso em 10 jan. 2017.

MORDFIN, Robin. The price of policy uncertainty. Chicago Booth Review. Chicago, 11 set, 2014. Disponível em: http://review.chicagobooth.edu/magazine/fall-2014/the-price-of-policyuncertainty. Acesso em 10 jan. 2017.

MOREIRA, A. T.; JONES, G. D. C.; TAVARES, M.; FEHR, L. C. F. A.; SILVA FILHO, O. A. Um estudo comparativo do Ebitda e do Fluxo de Caixa Operacional em Empresas Brasileiras do Setor de Telecomunicações. Revista de Gestão, Finanças e Contabilidade, v. 4, n. 3, p. 5-22, 2014. DOI: http://dx.doi.org/10.29386/rgfc.v4i3.720

NARDI, P.; NAKAO, S. Gerenciamento de resultados e a relação com o custo da dívida das empresas brasileiras abertas. Revista Contabilidade \& Finanças, v. 20, n. 51, p. 77-100, 2009. DOI: http://dx.doi.org/10.1590/S1519-70772009000300006.

NORTH, D. C. Transaction costs, institutions, and economic performance. São Francisco, CA: ICS Press, 2010.

PÁSTOR, L.; VERONESI, P. Uncertainty about government policy and stock prices. The Journal of Finance, v. 67, n 4, p. 1219-1264, 2012. DOI: https://doi.org/10.1111/j.15406261.2012.01746.x

PÁSTOR, L.; VERONESI, P. Political uncertainty and risk premia. The Journal of Financial Economics, v. 110, p. 520-545, 2013. DOI: 10.1016/j.jfineco.2013.08.007

PEREIRA, L. H. M.; MARTINS, O. S. Rating de crédito, governança corporativa e desempenho das empresas listadas na BM\&FBovespa. Revista de Gestão, v. 22, n. 2, p. 205221, 2015. DOI: https://doi.org/10.5700/rege559

NUNES, D. M. S.; MEDEIROS, O. R. Incerteza Política: Análise do impacto da incerteza política no prêmio de risco. Revista de Globalizacion, Competitividad y Gobernabilidad, v. 10, n. 2, p. 16-32, 2016. DOI: 10.3232/GCG.2016.V10.N2.01.

NUNES, D. M. S. Incerteza Política: Uma análise do impacto da incerteza política nacional e internacional no mercado de capitais brasileiros. 2017. Tese (Doutorado em Administração) - Programa de Pós-Graduação em Administração - Universidade de Brasília, Brasília, 2017.

RODRIGUES, S. S.; GALDI, F. C. Relações com investidores e assimetria informacional. Revista Contabilidade \& Finanças - USP, v. 28, n. 74, p. 297-312, 2017. DOI: $10.1590 / 1808-057 \times 201703630$

ROTHBARD, M. N. Economic depressions: Their cause \& cure. Auburn, Alabama: Ludwig Von Mises Institute, 2009. 
SADORSKY, P.V. Assessing the impact of oil prices on firms of different sizes: its tough being in the middle. Energy Policy, v. 36, p. 3854-3861, 2008. DOI: https://doi.org/10.1016/j.enpol.2008.07.019

SANTOS, R. L. ; DA SILVEIRA, A. D. M. Board interlocking no Brasil: a participação de conselheiros em múltiplas companhias e seu efeito sobre o valor das empresas. Revista Brasileira de Finanças, v. 5, n. 2, p. 125-163, 2007.

SCHUMPETER, J. A. Teoria do desenvolvimento econômico: uma investigação sobre lucros, capital, crédito, juro e o ciclo econômico. São Paulo: Abril Cultural, 1997.

VOTH, H. J. Stock price volatility and political uncertainty: Evidence from the interwar period. Working paper, UPF, p. 1-41, 2002.

WILLIAMSON, O. E. The economic institutions of capitalism: firms, markets, relational contracting. Free Press, 1985.

ZHU, Q.; SINGH, G. The impacts of oil price volatility on strategic investment of oil companies in North America, Asia, and Europe. Pesquisa Operacional, v. 36, n. 1, p. 1-21, 2016. DOI: https://doi.org/10.1590/0101-7438.2016.036.01.000 